\title{
Promoting E- Governance Culture in Higher Education Institutions
}

\author{
Mr. Sanjeet Kumar Tiwari ${ }^{1}$ Mr. Jubraj Khamari ${ }^{2}$ Anjali Singh ${ }^{3}$ \\ 1.Deptt. Of School Of Education, MATS University, Arang, Raipur, (C.G) - INDIA \\ 2.Deptt. Of School Of Education, MATS University, Arang, Raipur, (C.G) - INDIA \\ 3.Deptt. Of Applied Sciences, Singhania University, Jhunjhunu, Rajasthan- INDIA
}

\begin{abstract}
Education is one of the most important factors in achieving the developmental goal of the country. It is the key to the national development. In India Education has seen massive growth in recent years. On one hand, this growth promises to produce more skilled individuals to fulfill needs of ever growing Indian economy and on the other hand it poses a huge challenge for the governing bodies like UGC, AICTE and others to maintain or improve the quality of education. E-Governance solution in the field of educational sector has changed the way administration, which is designed to make the system user-friendly, time saving and cost saving also. Many of them are flexible enough to adapt to the changing educational environment efficiently and quickly and effectively. It is an integrated solution in the education sector that facilitates the processing and maintenance of large volumes of information such as: registration, admission, student information, classes, time table, transport, attendance, library, salary, expenses, examinations, performance, grades, hostels, security, reports, management, transport, staff details and fees among various departments in a higher education institution.
\end{abstract}

Keywords:- Higher Education Service System, Digitization, Electronic Books Management, E- Learning, Radio Frequency Identification.

\section{Introduction}

Education is one of the most important factor in achieving the development goal of a country. It is the key to the national development. In India Education has seen massive growth in recent years. On one hand, this growth promises to produce more skilled individuals to fulfill the needs of ever growing Indian economy and on the other hand it poses a huge challenge for the governing bodies like UGC, AICTE and others to maintain or improve the quality of education. An integrated Higher Education Service System (HESS) at a national level can be one of the key Information and Communication Technology initiatives to help India become a provider of world class education.

This system can provide deep visibility to governing bodies at a university and student level to analyze their performance and hence gear up for future requirements. On the other hand E-Governance solution in the field of educational sector has changed the way administration is being done now. The solution incorporates whole data and processes of an educational Institution into a unified system, making the process uncomplicated, well-organized and error proof. The solution is designed to make the system user-friendly, time saving and cost saving also. Many of them are flexible enough to adapt to the changing educational environment efficiently and quickly. E-Governance helps in improving transparency, providing speedy information, dissemination, improving administrative efficiency and public services in all the aspects of education.

Educational institutions may have various requirements that include computerization and management of processes such as registration, admission, student information, classes, time table, transport, attendance, library, salary and expenses, examinations, performance, grades, hostels, security and reports. Many of the software providers allow their clients to choose from the available modules to suit their needs. In this paper, an attempt has been made to discuss the concept of E-Governance and use of latest application and initiatives in education sector.

\subsection{Promoting}

\section{Operational Meaning}

In this research study the word promoting used so as to the operational meaning of the term used as the advancement, innovative, competitive and prospective uses \& utilization of systematic custom and tradition of system in Higher Education system with reference to E-Governance Culture. 


\subsection{E-Governance Culture}

E-governance can be defined as delivery of government services and information to the public using electronic means. Such means of delivering information is often referred to as ICT. Use of ICTs in government facilitates an efficient, speedy and transparent process for disseminating information to the public and other agencies, for providing services, and for performing administrative activities. E-governance enables the Government and Citizens to access easily, to improve new class of quality of services and to provide multichannel service delivery system. The vision of e-governance is to transform service delivery through the use of IT and Multimedia.

\subsection{Higher Education Institution}

In this study the Higher education Institution terms as all the Colleges of Raipur district specifically refers to UG and PG level colleges.

\subsection{Objectives :-}

\section{Methodology}

- To Study on Overview of E-Governance

- To Study on Digitization and Electronic Books Management

- To Study on E- Learning

- To Study on Benefits of E- Learning

- To Study on Distance Education System

- To Study on Radio Frequency Identification (RFID)

3.2 Method of the study

- To Study on Benefits of RFID

For the present study researchers used survey method of research to complete the research work systematically and successfully.

\subsection{Population of the study}

The Population of the present study constituted all Higher Education Institutions in Raipur district of Chhattishgarh state.

\subsection{Sample of the study}

Researchers have selected one Higher Education Institution by Purposive Sampling Method out of total population.

\subsection{Tools}

Researchers have used Questionnaire to collect data from the sample as relevance tool in the study.

\subsection{Statistical Techniques}

Researchers used the Simple Percentage method for analyze \& interpretation of the collected data.

\subsection{Limitation of the study}

The present study limited to all Higher Education Institutions of Raipur district of chhattishgarh state.

\subsection{Overview of E-Governance}

\section{Findings and Discussion}

- E-governance solution in the field of educational sector has changed the way administration, which is designed to make the system user-friendly, time saving and cost saving also. Many of them are flexible enough to adapt to the changing educational environment efficiently and quickly and effectively.

- It is an integrated solution in the education sector that facilitates the processing and maintenance of large volumes of information such as: registration, admission, student information, classes, time table, transport, attendance, library, salary, expenses, examinations, performance, grades, hostels, security, reports, management, transport, staff details and fees among various departments in an institution.

- E-governance requires several elements of good governance, such as transparency, accountability, participation, social integration, public financial management reform and development. It includes a very broad range of services for almost all segments of society. 


\subsection{Positive aspects of E-Governance}

The benefits of e-governance in an educational sector are improved efficiency, increase in transparency and accountability of educational administrative activities convenient and faster access to services, and lower costs for administrative services. The multi-faceted benefits of e-governance can be described as under these points:

- Increase the efficiency of the various departments and reduces duplication

- Preparation of reports becomes easy and quicker.

- Harassment of the students is reduced.

- Easy online information and submission of forms and payment also becomes almost immediate.

- The management, faculty members, students and administrative staff get connected to the each other more easily leading to enhanced efficiency in delivering service by the way of faster dissemination of information that on a very low cost.

- Equal opportunity to access to information is provided regardless of one's physical location and physical disability thus removing distance barriers.

- Leads to significant reduction of transaction costs, time, space, and manpower.

\subsection{Digitization and Electronic Books Management}

- Considering the impact of IT in every discipline, new technologies are emerging even in the library systems, giving way to e-books (electronic books), as well as digital knowledge centre and their access mechanisms. Online catalogues, full-text search and retrieval facilities, automated record keeping, computer-based decision-making and so on.

- A digital library could provide access to an unlimited number of copies at the "touch of a button". A text or monograph, which is available in an electronic form that can be obtained electronically, with the help of ICT it is also easy to carry large number of e-books in pocket PC at one time.

- The main benefit of digitization service is that it cuts down the requirement of papers, saves office space and cuts down the time needed to process the same information. With this service, we can convert the physical data in form of papers, thesis, research papers, magazines, books, records, forms, mark sheet, survey data and others into the digital format which is readable by all computers and is easily processed by users.

- Use of scanner and other software tools to scan a page/file in to the computer and converting the scanned data in to readable/editable characters. Software includes OCR software. OCR stands for Optical Character Reader; they can read the data from image files.

- Use of computer typists/data entry operators as they are called to punch in the data on to a desired file format. (MS Word, Excel, Access etc) Both or either can be used for successful digitization works. Digital data can be easily stored, backup copies can be maintained as well as distributed quite easily. Hence, with our digitization services the cost of further digitization goes down enormously. This also ensures faster and simple sharing of the data.

\subsection{E- Learning}

- E-Learning is the use of technology to enable people to learn anytime and anywhere. E-Learning can include training, the delivery of just-in-time information and guidance from experts. E- learning covers a wide set of applications and processes including computer-based learning, web-based learning, virtual classrooms and digital collaboration. The e-Learning System has powerful capabilities for managing courses and tailoring instructions to meet student needs.

- Electronic learning or e-learning is a type of education where the medium of instruction is computer technology. It involves planned teaching or teaching experiences that use a wide spectrum of technologies mainly the internet to reach learners at a distance.

\subsection{Benefits of E- Learning:}

- E-learning has become popular amongst educationists because of its strengths and advantages provide the better access to educational resources from outside the institution on a global and instant basis.

- Increased and flexible interaction with student through e-mail and discussion forums.

- It is an opportunity for international, cross-cultural and collaborative learning. Communication capabilities allow students and faculty to discuss issues online, to schedule collaborative sessions and to form groups that enable teamwork across geographic boundaries and extend learning beyond the classroom.

\subsection{Radio Frequency Identification (RFID)}

RFID is wireless technology that uses Radio Frequency (RF) electromagnetic energy to carry information between an RFID tag and an RFID reader. In recent years, automatic identification procedures have 
become very popular. Rapid development in information technology has brought a revolutionary change in the field of library system and services. RFID have been used to improve the quality of services and to theft detection in the libraries. It is used for library transaction, inventory function and theft detection system. The system provides an intelligent way for libraries to maximize their investment in RFID with optimized memory. RFID systems offering, and has built strong partnerships with library automation equipment providers to offer complete integrated solutions for libraries management.

\subsection{Benefits of RFID:}

- RFID tags replace both the bar code and EAS (anti-theft) device allowing for much faster conversion of library materials in new branches. In existing libraries, RFID tags can co-exist with existing EM anti-theft systems.

- Book returns can be automated with check-in.

- Fast on-the-shelf inventory allows for much better accuracy in collection management.

\subsection{Distance Education System}

Since traditional education system was unable to cope with the current needs, therefore, Distance

Education System took birth to cope with the current and future needs of the educational development. The use of ICT has extended the scope of offering educational programs at a distance. The off-campus delivery was an option for students who were unable to attend the classes regularly. Today many students are able to make this choice through technology facilitated learning setting. This helps in time and cost saving and extending courses of choice to students of different backgrounds, cultures and perspectives. Learners are free to participate in learning activities at their convenience through online technologies. Eminent teachers form different parts of the country and abroad cab be utilized for teaching at their convenience through mobile technologies and seamless communication technologies that support $24 * 7$ teaching and learning like NPTEL (National Program on Technology Enhanced Learning, India 2007), EKLAVYA Technology Channel, India, 2007, etc.

\section{Conclusion}

The planning for efficient administration of educational institutions, increasing Global communication skill, to achieve the world class standard it is necessary to have a improved collaboration and access to information available in all the parts of the world are possible only by introducing IT in Educational Sector with e-governance as a security for maintaining standard. Today the IT has become an integral part of life of the people in the world. It is the time to applying the skill for the betterment of Indian educational system as well.

The e-governance needs security for smooth information flow, best practice database and enhanced capacity for information analysis etc, Government should support by enacting favorable legislations and updated amendments for maintaining standards in the educational process and improvements in the related field. It requires completely new infrastructure, procedures, policies and working skills for producing and collecting online information. With the advent of ICT, electronic governance is an emerging trend to re-invent the way the government works, becoming a new model of governance. Such a comprehensive and integrated system can also enable authorities to analyze the performance of one of the best performing institutes and compare it with other schools and colleges to identify the gaps. Also, the system can obtain feedback from students to modify course curriculum if deemed appropriate by the authorities. This will allow all the low-performing schools and colleges to reduce the gap with better performing institutes. It will be help in the betterment of the higher education in the country and increase the number of employable students. Education system can fully equip our children to meet the ever evolving demands in today's highly-competitive environment; the education system needs to be made more efficient and effective by implementing e-governance. It is high time our educators think in terms of imparting what is known as life-long education, or, more aptly, life-long self-education.

\section{References}

[1] Satheesh, K.(2010), 'Educational Management, leadership, Administration \& School and Community' [online] Available form: http://sathitech.blogspot.com (Accessed 26-12-2011)

[2] Mishra, J. (2007), Mobile Learning: It's Implication in Education and Training, University News, Vol. 45(34), August 20-26, p. 15.

[3] The Times of India, (2011) 'How e-governance will revitalise education sector' [online] Available form:http://articles.timesofindia.indiatimes.com/2011-06- 08/education/296336071 e-governance-education-sector-highereducation (Accessed 28-12-2011)

[4] Bhadauria, Mridula and Gore Rashmi (2004), Innovative Communication Techniques in Higher Education, University News, Vol. 42(29), July 19-25, pp. 5-8.

[5] E-governance in education [online] Available form: http://www.universityerp.com/egovernance. shtml (Accessed 11-12-2011)

[6] Jibin, V. K. and Naseema, C. (2011), 3G Mobile Learning: Innovation in Education, University News, Vol. 49(06), Feb 07-13, pp. 28-31.

[7] Kaka Saverinus, Pd.S. (2008) 'The Role of ICT in Education Sector' [online] Available form: http://verykaka.wordpress.com/2008/07/25/the-role-of-ict-in-education-sector. (Accessed 26-12-2011) 